\title{
Sosialisasi Strategi dan Web Pemasaran Online (PPDM di Desa Rasau Jaya Satu)
}

\author{
Linda Suwarni1 ${ }^{*}$, Eko Sarwono ${ }^{2}$, Edy Suryadi $^{3}$, Selviana $^{4}$ iD \\ 1,4 Program Studi Kesehatan Masyarakat, Fakultas Ilmu Kesehatan, Universitas Muhammadiyah Pontianak, Indonesia \\ ${ }^{2}$ Program Studi Teknik Mesin, Fakultas Teknik, Universitas Muhammadiyah Pontianak, Indonesia \\ ${ }^{3}$ Program Studi Manajemen, Fakultas Ekonomi dan Bisnis, Universitas Muhammadiyah Pontianak, Indonesia \\ *Corresponding author: suwarniilin6@gmail.com
}

\begin{abstract}
Pandemi Covid-19 yang terjadi berdampak pada berbagai aspek kehidupan, termasuk pada Usaha Kecil dan Menengah (UKM). UKM Mekar Sari dan Sekapur Sirih yang bergerak dalam bidang produksi rengginang, jagung marning, kerupuk beras, dan keripik tahu juga terdampak akibat pandemic ini. Keterbatasan dalam pemasaran yang saat ini tidak bisa secara konvensional menyebabkan penurunan pendapatan mitra. Permasalahan lain adalah ketidaktahuan mitra tentang strategi pemasaran online. Tujuan kegiatan pengabdian ini adalah untuk memperkenalkan tentang strategi pemasaran online dan web pemasaran online. Potensi yang dimiliki oleh mitra adalah memiliki kemauan dan semangat yang tinggi untuk terus belajar. Berdasarkan kesepakatan tim pengabdi dengan mitra, maka solusi yang dilakukan dalam mengatasi permasalahan tersebut adalah dengan sosialisasi strategi dan penyediaan web pemasaran online melalui program pengembangan desa mitra (PPDM) di tahun ketiga. Metode kegiatan menggunakan ceramah dan demonstrasi pengelolaan web pemasaran online. Kegiatan pengabdian ini terlaksana dengan baik. Terjadi peningkatan pengetahuan khalayak sasaran sebesar 57,4\% antara sebelum dan setelah dilakukan kegiatan pengabdian ini. Pihak pemerintah desa perlu melakukan pendampingan melalui Badan Usaha Milik Desa (BumDes) agar pemasaran online ini tetap berjalan optimal.
\end{abstract}

Keywords: Pemasaran Online, Web, PPDM

\section{Abstract}

The Covid-19 pandemic that occurred had an impact on various aspects of life, including Small and Medium Enterprises (UKM) in Rasau Jaya Satu Village. The purpose of this devotion activity is to introduce about online marketing strategies and online web marketing in Rasau Jaya Satu Village. UKM Mekar Sari and Sekapur Sirih are partners in this service activity which is engaged in the production of rengginang, marning corn, rice crackers, and tofu chips which were also affected by this pandemic. Limitations in marketing that currently cannot conventionally lead to a decrease in partner income. Another problem is partners' ignorance of online marketing strategies. Partners have the potential to have a high willingness and enthusiasm to continue learning. Based on the agreement of the Pontianak UM service team with partners, the solution taken to overcome these problems is by socializing the strategy and providing online web marketing through the partner village development program (PPDM) in the third year. The method of activity uses lectures and demonstrations of online web marketing management. This service activity was carried out well. There was an increase in the knowledge of the target audience by $57.4 \%$ between before and after this service activity. The village government needs to provide assistance through Village-Owned Enterprises (BumDes) so that online marketing continues to run optimally.

\section{Introduction}

Pandemi Covid-19 yang belum berakhir hingga saat ini membawa dampak yang besar bagi berbagai sektor. Dampak yang lebih besar bahwa pandemic ini berdampak pada

$\begin{array}{lll}\text { History: } & & \text { Publisher: Undiksha Press } \\ \text { Received } & : 02 \text { August } 2020 & \text { Licensed: This work is licensed under } \\ \text { Revised } & : 09 \text { September } 2020 & \text { a Creative Commons Attribution 3.0 License } \\ \text { Accepted } & : 06 \text { October } 2020 & \text { CC OP OP } \\ \text { Published } & : \text { : } 30 \text { November } 2020 & \end{array}$


ancaman krisis ekonomi (Hossain, 2020). Dampak yang paling terasa pada ekonomi dunia, termasuk bidang perekonomian domestic termasuk Usaha Kecil dan Menengah (UKM). Keberadan UKM di Indonesia sudah terbukti mampu untuk menjadi roda penggerak ekonomi di masa krisis (Lastina \& Budhi, 2018). UKM dapat diartikan sebagai penyelamat dalam pembangunan ekonomi pasca krisis sebab UKM mampu mengurangi tingkat pengangguran dan memberikan kesempatan kerja (Mutiarasari, 2018). Kurun waktu 5 tahun terakhir menunjukkan bahwa sektor UKM meningkatkankan Produk Domestik Bruto (PDB) sebesar 2,5\% (Gunartin, 2017).

UKM Mekar Sari dan Sekapur Sirih adalah dua diantara banyak UKM yang ada di Desa rasau Jaya Satu yang juga terkena dampak pandemic Covid-19. Pemasaran yang masih konvensional menjadi permasalahan utama, apalagi di tengah pandemic seperti sekarang ini. UKM Mekar Sari bergerak dalam bidang produksi rengginang, marning, dan kerupuk nasi, sedangkan UKM Sekapur Sirih dalam bidang produksi keripik tahu. Kedua ketua UKM menyatakan bahwa terjadi penurunan yang signifikan terhadap penjualan dibandingkan sebelum terjadinya pandemic. Berdasarkan permasalahan tersebut maka kegiatan Program Pengembangan Desa Mitra (PPDM) oleh tim pengabdi LPPM UM Pontianak di tahun ketiga berfokus pada sosialisasi strategi dan web pemasaran online. Strategi pemasaran online merupakan strategi yang efektif bagi UMKM di era revolusi 4.0 (Hadi \& Ardhi Khairi, 2020; Husnurrosyidah, 2019; Reza, 2016; Saraswati, 2020) Perkembangan teknologi dan informasi saat ini yang begitu pesat sangat berpengaruh signifikan dalam semua sektor bisnis, termasuk pada UKM.

Pemasaran online melalui web (teknologi digital) saat ini sudah banyak digunakan dalam seluruh aspek kehidupan manusia, sehingga pada pelaku usaha (termasuk UKM) harus bisa beradaptasi dengan kemajuan teknologi yang ada agar dapat terus berjalan dan berkembang. Digital marketing ini merupakan cara berinteraksi antara pembeli dan penjual tanpa batas waktu dan geografis (Purwana et al., 2017; Selander et al., 2013). Kegiatan jual beli melalui online harus memperhatikan kejelasan informasi dari produk yang diperjual belikan, selain itu kemasan (packaging) produk juga sangat penting. Hal ini akan mempengaruhi keberhasilan usaha dalam digital marketing (Christine, 2000; Pradiani, 2018). Selain melalui web pemasaran, dapat juga memanfaatkan media sosial dalam pemasaran produk UKM (Puspitasari et al., 2019). Strategi pemasaran online berpengaruh signifikan terhadap minat beli konsumen (Jati \& Yuliansyah, 2017; Sarastuti, 2017). Salah satu yang perlu diperhatikan dalam pemasaran online adalah benchmarking, yaitu bagian dari manajemen untuk menganalisa seberapa besar produk memberikan kepuasan kepada konsumen (Fadly \& Sutama, 2020; Putri, 2016b). Hal ini juga didukung dan diperkuat oleh penelitian yang sudah ada sebelumnya terkait dengan strategi pemasaran online dan benchmarking (Syahputra, 2017; Thousani et al., 2015; Wahana et al., 2014). Jadi, pemasaran online akan mempengaruhi keberhasilan usaha dalam digital marketing.

Tujuan kegiatan pengabdian ini adalah untuk memperkenalkan tentang strategi pemasaran online dan web pemasaran online di Desa Rasau Jaya Satu. Kegiatan ini juga melibatkan Badan Usaha Milik Desa (Bumdes) Desa Rasau Jaya Satu sebagai pengelola web pemasaran di tingkat desa. Diharapkan melalui kegiatan ini dapat meningkatkan pengetahuan mitra dalam strategi pemasaran online dan memanfaatkan web pemasaran online, sehingga dapat meningkatkan pendapatan mitra UKM yang ada.

\section{Materials and Methods}

UKM-UKM yang ada di Desa Rasau Jaya Satu dan pengurus Badan Usaha Milik Desa (Bumdes) menjadi khalayak sasaran dalam kegiatan pengabdian program pengembangan desa mitra. Jumlah peserta dalam kegiatan ini adalah sebesar 20 orang. Kegiatan pengabdian ini dilaksanakan pada hari Selasa tanggal 11 Agustus 2020 bertempat di 
Aula Kantor Desa Rasau Jaya Satu mulai pukul 08.00-13.30. Metode yang digunakan dalam melaksanakan kegiatan pengabdian ini adalah sosialisasi strategi pemasaran online dan mengenalkan web pemasaran online di Desa Rasau Jaya Satu Kecamatan Rasau Jaya Kabupaten Kubu Raya. Sosialisasi informasi ini melalui metode ceramah dan praktek secara teknis dalam mengelola web pemasaran online. Setelah materi disampaikan kemudian dilanjutkan dengan sesi diskusi agar para peserta yang mengikuti kegiatan dapat memahami materi yang disampaikan. Pengukuran keberhasilan informasi yang diketahui dengan memberikan pertanyaan seputar materi sebelum dan setelah dilakukan kegiatan sosialisasi.

\section{Results and Discussion}

Kegiatan pengabdian ini dilaksanakan pada saat pandemi Covid-19 masih berlangsung sehingga pelaksanaan kegiatan mengikuti protokol kesehatan. Pada saat awal kegiatan diberikan edukasi tentang adaptasi kebiasaan baru pada era pandemi Covid-19 di tempat kerja. Peserta kegiatan pengabdian ini berjumlah 20 orang, yang terdiri dari UKMUKM yang ada di Desa Rasau Jaya Satu, pengurus Badan Usaha Milik Desa (BumDes), dan perwakilan dari pemerintahan Desa Rasau Jaya Satu. Kegiatan kemudian dilanjutkan dengan penyampaian strategi pemasaran online melalui penyuluhan, dan dilanjutkan dengan pengelolaan web pemasaran online melalui demonstrasi. Kegiatan di tunjukkan pada gambar 1 dan 2 berikut.

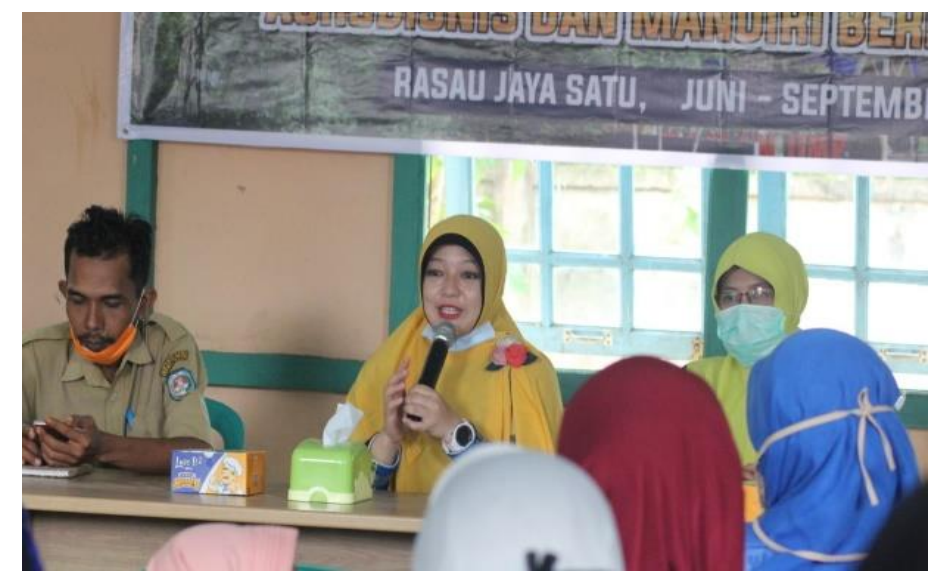

Gambar 1. Edukasi tentang Adaptasi Kebiasaan Baru di Tengah Pandemi Covid-19

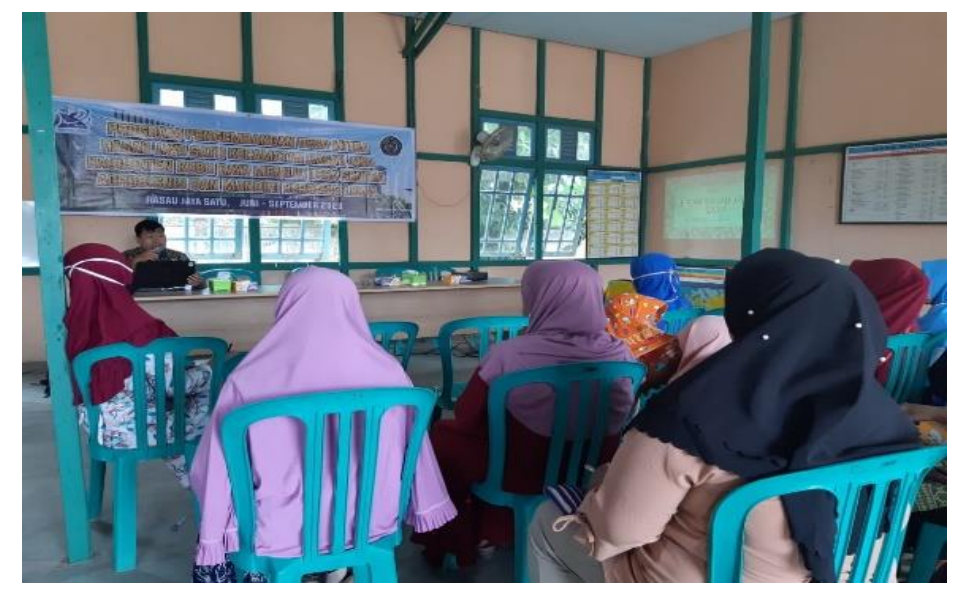

Gambar 2. Pengabdi Sedang Memberikan Sosialisasi tentang Strategi Pemasaran Online 
Pengukuran tingkat keberhasilan kegiatan yang dilakukan pada sasaran yaitu dengan memberikan kuesioner pretest sebelum kegiatan pengabdian dilakukan, dan setelahnya diberikan posttest. Hasil evaluasi yang ada menunjukkan terjadinya peningkatan skor pengetahuan khalayak sasaran antara sebelum dan sesudah dilakukan kegiatan. Terjadi peningkatan pengetahuan khalayak sasaran (skor mean) antara sebelum dan setelah diberikan pengetahuan sebesar 31,9 (sebesar 57,4\%). Hal ini menunjukkan bahwa kegiatan pengabdian yang dilakukan berhasil meningkatkan pengetahuan khalayak sasaran tentang pemasaran online.

Pemasaran online melalui web (teknologi digital) saat ini sudah banyak digunakan dalam seluruh aspek kehidupan manusia, sehingga pada pelaku usaha (termasuk UKM) harus bisa beradaptasi dengan kemajuan teknologi yang ada agar dapat terus berjalan dan berkembang. Digital marketing ini merupakan cara berinteraksi antara pembeli dan penjual tanpa batas waktu dan geografis (Purwana et al., 2017; Selander et al., 2013; Syamsiah, 2018). Kegiatan jual beli melalui online harus memperhatikan kejelasan informasi dari produk yang diperjual belikan, selain itu kemasan (packaging) produk juga sangat penting. Hal ini akan mempengaruhi keberhasilan usaha dalam digital marketing (Christine, 2000; Irrubai, 2015; Pradiani, 2018). Selain melalui web pemasaran, dapat juga memanfaatkan media sosial dalam pemasaran produk UKM (Nuryskha et al., 2015; Puspitasari et al., 2019). Strategi pemasaran online berpengaruh signifikan terhadap minat beli konsumen (Akhmad, 2015; Jati \& Yuliansyah, 2017; Khazim, 2016; Sarastuti, 2017). Salah satu yang perlu diperhatikan dalam pemasaran online adalah benchmarking, yaitu bagian dari manajemen untuk menganalisa seberapa besar produk memberikan kepuasan kepada konsumen (Fadly \& Sutama, 2020; Putri, 2016b). Hal ini juga didukung dan diperkuat oleh penelitian yang sudah ada sebelumnya terkait dengan strategi pemasaran online dan benchmarking (Syahputra, 2017; Thousani et al., 2015; Wahana et al., 2014). Dalam sosialisasi pemasaran online, juga disampaikan terkait dengan benchmarking. Benchmarking merupakan bagian dari proses menemukan style baru yang lebih baik dalam melakukan sesuatu, dalam hal ini adalah produk. Terbukti dari penelitian sebelumnya bahwa desain strategi pemasaran online signifikan melalui evaluasi benchmarking (Putri, 2016) Beberapa tahapan yang perlu dilakukan dalam proses benchmarking, antara lain plan, search, observe, analyze, dan adapt (Paulus \& Devie, 2013).

Tidak jauh berbeda dengan strategi pemasaran secara umum, dalam pemasaran online juga menggunakan marketing mix. Program pemasaran yang efektif melalui memadukan seluruh elemen dalam upaya memberikan nilai terbaik kepada konsumen. Brand (Merek) merupakan salah satu atribut yang penting dari sebuah produk yang menjelaskan identitas produk. Seiring dengan perkembangan pasar dengan semakin banyak produk dan ketatnya persaingan, komunikasi pemasaran mengalami perkembangan dan bertransformasi menjadi lebih terintegrasi yang dikenal dengan istilah komunikasi pemasaran terpadu "the marketing communication mix". Komunikasi pemasaran terpadu sudah menjadi tren dan merupakan elemen penting dalam dunia pemasaran, dimana elemen komunikasi dan pemasaran merupakan elemen terintegrasi yang tidak dapat dipisahkan untuk meraih sukses (Chrismardani, 2014).

Hal yang perlu diperhatikan dalam pemilihan strategi pemasaran (termasuk pemasaran online) adalah faktor internal terdapat beberapa hal yaitu kekuatan (bahan baku yang berkualitas, brand image yang baik, harga yang terjangkau, serta intergrasi dengan kelompok) dan kelemahan (distribusi yang kurang merata, produk yang rentan rusak, promosi yang kurang maksimal, serta sumber daya pemasaran yang kurang). Selain itu, terdapat faktor eksternal yang menjadi perhatian perusahaan yaitu peluang dan ancaman. Untuk peluang yang dimiliki perusahaan adalah daya beli meningkat, pasar potensial serta perubahan gaya 
hidup. Namun demikian, terdapat beberapa hal yang menjadi ancaman perusahaan yaitu isu kesehatan, pasar bebas, produk pesaing. Rumusan alternatif strategi yang didapatkan berdasarkan faktor-faktor eksternal dan internal adalah bekerjasama dengan partner, diferensiasi produk, promosi gabungan dengan grup Charoen Pokphand, serta promosi edukatif (Wibowo et al., 2018). Peningkatan pangsa pasar merupakan hasil dari diferensiasi produk (Belangkaehe et al., 2014). Beberapa hal yang dapat menjadi pembeda dalam industri pangan adalah rasa dan desain kemasan. Desain kemasan adalah suatu kegiatan merancang dan memproduksi wadah untuk suatu produk. Bagian dari desain kemasan berkaitan dengan fitur-fitur fisik kemasan, dan terdiri dari tiga sub dimensi: bentuk, ukuran, dan material (Nugroho et al., 2017)

Kegiatan ini ditutup dengan pemberian web pemasaran online melalui BumDes Desa Rasau Jaya Satu yang disaksikan oleh sekretaris pemerintahan desa, dan peserta kegiatan. Diharapkan web pemasaran ini dapat berjalan secara terus menerus dan meningkat pendapatan UKM-UKM yang ada di Desa Rasau Jaya Satu Kecamatan Rasau Jaya Kabupaten Kubu Raya. Berikut dokumentasi penyerahan web pemasaran online secara simbolis:

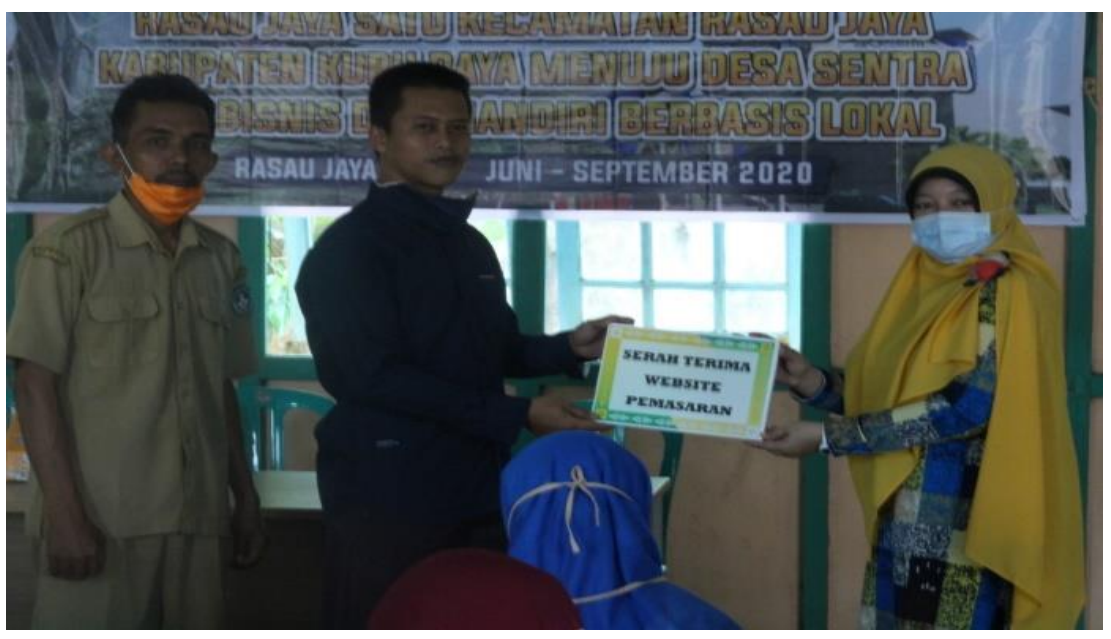

Gambar 3. Serah Terima Secara Simbolis Web Pemasaran UKM Desa Rasau Jaya Satu

Pengelolaan web pemasaran UKM desa ini akan diintegrasikan dengan rumah kemasan dan pemasaran yang sudah terbentuk di UKM binaan UM Pontianak sebelumnya di Desa Rasau Jaya Satu (UKM Mekar Sari dan Sekapur Sirih). Tim pengabdi LPPM UM Pontianak tetap melakukan pendampingan kepada khalayak sasaran sampai dengan bulan September 2020, untuk mengevaluasi kegiatan yang dilakukan.

\section{Conclusion}

Kegiatan pengabdian dalam bentuk Program Pengembangan Desa Mitra (PPDM) tahun ketiga ini adalah sosialisasi strategi pemasaran dan web pemasaran online berjalan dengan baik dan lancar. Hasil evaluasi menunjukkan terjadi peningkatan skor mean pengetahuan khalayak sasaran antara sebelum dan setelah dilakukan kegiatan pengabdian. Pengelolaan web pemasaran online ini dikelola oleh Badan Usaha Milik Desa (BumDes) yang membantu pemasaran produk-produk yang dihasilkan UKM yang ada di Desa Rasau Jaya Satu. Disarankan kepada pemerintah Desa Rasau Jaya Satu agar dapat selalu mendampingi UKM-UKM yang ada di Desa Rasau Jaya Satu melalui Badan Usaha Milik Desa (BumDes) agar kegiatan pemasaran online bisa terus berlanjut. 


\section{References}

Akhmad, K. A. (2015). Pemanfaatan Media Sosial bagi Pengembangan Pemasaran UMKM (Studi Deskriptif Kualitatif pada Distro di Kota Surakarta). Duta.Com, 9(September), 43-54.

Belangkaehe, R., Engka, D., \& Mandeij, D. (2014). Anaisis struktur pasar, perilaku dan kinerja industri perbankan Indonesia ( studi pada bank yang terdaftar di BEI periode 2008-2012 ). Jurnal Berkala Ilmiah Efisiensi, 14(3), 43-55. https://ejournal.unsrat.ac.id/index.php/jbie/article/view/5461/4968

Chrismardani, Y. (2014). Komunikasi Pemasaran Terpadu: Implementasi Untuk Umkm. Neo-Bis, 8(2), 179-189. https://doi.org/10.21107/NBS.V8I2.472

Christine, S. C. (2000). Peranan Desain Kemasan Dalam Dunia Pemasaran. Nirmana, 2(2), 92-103. https://doi.org/https://doi.org/10.9744/nirmana.2.2.

Fadly, H. D., \& Sutama. (2020). Membangun pemasaran online dan digital branding ditengah pandemi covid-19. Jurnal Ecoment Global : Kajian Bisnis Dan Management, 5, 213222.

Gunartin. (2017). Penguatan Umkm Sebagai Pilar Membangun Ekonomi Bangsa. Jurnal Pendidikan, Hukum, Dan Bisnis, 2(2), 1-10.

Hadi, A. S., \& Ardhi Khairi. (2020). Pemilihan Strategi Pemasaran Di Era Digital Pada Kelompok Ibu Pkk Desa Gadingharjo. Dinamisia: Jurnal Pengabdian Kepada Masyarakat, 4(1), 127-132. https://doi.org/10.31849/dinamisia.v4i1.3246

Hossain, M. (2020). The effect of the Covid-19 on sharing economy activities. Journal of Cleaner Production, xxxx, 124782. https://doi.org/10.1016/j.jclepro.2020.124782

Husnurrosyidah. (2019). E-Marketplace UMKM Menghadapi Revolusi Industri 4.0 dalam Perspektif Islam. Jurnal Ekonomi Syariah, 7(2), 224-239. journal.stainkudus.ac.id/index.php/equilibrium

Irrubai, M. L. (2015). Strategi Labeling, Packaging dan Marketing Produk Hasil Industri Rumah Tangga Di Kelurahan Monjok Kecamatan Selaparang Kota Mataram Nusa Tenggara Barat. Jurnal Jurusan Pendidikan IPS Ekonomi, 6(1), 15-30.

Jati, W., \& Yuliansyah, H. (2017). Pengaruh Strategi Pemasaran Online (Online Marketing Strategy) Terhadap Minat Beli Konsumen (Studi Kasus Pada Toko Online Shop Azzam Store). Jurnal Pemasaran Kompetitif, 1(1), 2598-2823. https://doi.org/http://dx.doi.org/10.32493/jpkpk.v1i01.679

Khazim, I. Al. (2016). Pengaruh Strategi Internet Marketing Terhadap Perilaku Konsumen Lazada.Co.Id Dalam Berbelanja Online Melalui Variabel Electronic Word of Mouth (Ewom). Jurnal Ilmiah Ekonomi Bisnis, 21(2), 178539.

Lastina, N. luh made A. danni, \& Budhi, M. K. S. (2018). Efektivitas Penyaluran Kredit Usaha Rakyat Pt. Bri (Persero) Unit Blahkiuh Terhadap Produktivitas Ukm Dan Pendapatan Ukm Penerima Kur Di Kecamatan Abiansemal. E-Jurnal Ekonomi Dan Bisnis Universitas Udayana, 7(4), 959. https://doi.org/10.24843/eeb.2018.v07.i04.p02

Mutiarasari, A. (2018). Peran Entrepreneur Meningkatkan Pertumbuhan Ekonomi dan Mengurangi Tingkat Pengangguran. Jurnal Prodi Ekonomi Syari'ah, 1(2), 1-114. http://e-jurnal.stail.ac.id/index.php/dinar/article/download/83/90

Nugroho, S., Pujotom, D., Ulkhaq, M. M., \& Permadi, D. T. (2017). Redesain Kemasan Makanan Ringan Olahan Pada Umkm Center Jawa Tengah Dengan Metode Kansei 
Engineering. 16(1), 77-86.

Nuryskha, Amani, H., \& Wulandari, S. (2015). Pemanfaatan Media Sosial Sebagai Komunikasi Pemasaran Usaha Kecil Menengah Rizqia Keripik Sambal Strawberry Dengan Metode Benchmarking. E-Proceeding of Engineering, 2(3), 7592-7599.

Paulus, M., \& Devie. (2013). Analisa Pengaruh Penggunaan Benchmarking Terhadap Keunggulan Bersaing dan Kinerja Perusahaan. Business Accounting Review, 1(2), 3949. http://publication.petra.ac.id/index.php/akuntansi-bisnis/article/view/569

Pradiani, T. (2018). Pengaruh Sistem Pemasaran Digital Marketing Terhadap Peningkatan Volume Penjualan Hasil Industri Rumahan. Jurnal Ilmiah Bisnis Dan Ekonomi Asia, 11(2), 46-53. https://doi.org/10.32812/jibeka.v11i2.45

Purwana, D., Rahmi, R., \& Aditya, S. (2017). Pemanfaatan Digital Marketing Bagi Usaha Mikro, Kecil, Dan Menengah (UMKM) Di Kelurahan Malaka Sari, Duren Sawit. Jurnal Pemberdayaan Masyarakat Madani (JPMM), 1(1), 1-17. https://doi.org/10.21009/jpmm.001.1.01

Puspitasari, A. F., Ervianty, R. M., Dwikesumasari, P. R., \& Dwijayanti, I. S. (2019). Interest of Using E-Commerce Channels Based on Social Media To Improve the Quality of Regional Superior Product Marketing on Female Group of Craftsmen From Sanitair Klaseman Malang City. Darmabakti Cendekia: Journal of Community Service and Engagements, 1(1), 16. https://doi.org/10.20473/dc.v1.i1.2019.16-21

Putri, N. A. (2016). Desain Strategi Pemasaran Online Pada Fullus Fashion Melalui Evaluasi Benchmarking. Jurnal Manajemen Dan Start-Up Bisnis, 1(1), 118-127.

Reza, F. (2016). Strategi Promosi Penjualan Online Lazada.Co.Id. Jurnal Kajian Komunikasi, 4(1), 64-74. https://doi.org/10.24198/jkk.vol4n1.6

Sarastuti, D. (2017). Strategi Komunikasi Pemasaran Online Produk Busana Muslim Queenova. Visi Komunikasi, $16(01), \quad$ 71-90. https://doi.org/http://dx.doi.org/10.22441/jvk.v16i1.1645

Saraswati, E. (2020). Strategi Perencanaan dan Biaya Pemasaran yang Efektif bagi UMKM Mitra Binaan PT. Semen Indonesia Tbk. Journal of Dedicators Community, 3(3), 97105. https://doi.org/10.34001/jdc.v3i3.1040

Selander, U., Henfridsson, O., \& Svahn, F. (2013). Capability Search and Redeem across Digital Ecosystems. Journal of Information Technology, 28, 183-197. https://doi.org/10.1007/978-3-662-59807-8_4

Syahputra, D. (2017). Analisis Tingkat Kepuasan Pelanggan Toyota Atas Relationship Marketing Dan Layanan Purna Jual Pada Pt. Agung Toyota Sutomo Di Pekanbaru. Jom Fekon, 4, 830-844.

Syamsiah. (2018). Pengaruh Kualitas Produk, Kualitas Pelayanan dan Harga Terhadap Keputusan Pembelian Pada Supermarket Transmart Carefour di Kota Makassar.

Thousani, H. F., Fauzi, A., \& Sunarti. (2015). Upaya Pengembangan E-Business Dalam Pemasaran Produk Secara Internasional( Studi pada Akademi Bisnis Online Indonesia Surabaya ). Jurnal Administrasi Bisnis, 23(1). http://administrasibisnis.studentjournal.ub.ac.id/index.php/jab/article/view/917 
Wahana, A., Suyanto, M., \& Amborowati, A. (2014). Analisis Penerapan Social Media Sebagai Strategi Bisnis Oleh Pelaku Bisnis Online Magister Teknik Informatika. Sisfotenika, 4(2), 152-162. https://doi.org/http://dx.doi.org/10.30700/jst.v4i2.34

Wibowo, M. E., Daryanto, A., \& Rifin, A. (2018). Strategi Pemasaran Produk Sosis Siap Makan (Studi Kasus: PT Primafood Internasional ). MANAJEMEN IKM: Jurnal Manajemen Pengembangan Industri Kecil Menengah, 13(1), 29. https://doi.org/10.29244/mikm.13.1.29-38 